\title{
A study of the symmetry of roots and root canal morphology in mandibular anterior teeth using cone-beam computed tomographic imaging in a Polish population
}

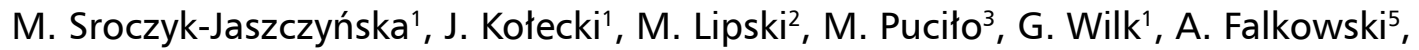 \\ K. Kot ${ }^{2}$, A. Nowicka ${ }^{4}$ \\ 'Department of General and Dental Radiology, Pomeranian Medical University in Szczecin, Poland \\ ${ }^{2}$ Department of Preclinical Conservative Dentistry and Preclinical Endodontics, \\ Pomeranian Medical University in Szczecin, Poland \\ IIndividual Dental Practice, Zielona Gora, Poland \\ ${ }^{4}$ Department of Conservative Dentistry and Endodontics, Pomeranian Medical University in Szczecin, Poland \\ ${ }^{5}$ Department of Interventional Radiology, Pomeranian Medical University in Szczecin, Poland
}

[Received: 12 July 2019; Accepted: 12 October 2019]

Background: The purpose of the study was to analyse mandibular anterior teeth in a Polish population and determine the symmetry of root and root canal morphology between the right and left side using cone-beam computed tomography (CBCT) scanning.

Materials and methods: From 111 CBCT examinations, 303 pairs of equivalent mandibular anterior teeth were analysed on the right and left sides to evaluate symmetry. Axial, sagittal, and cross-sectional slices with a thickness of 0.2-0.25 mm were used. The number of root canals and their internal patterns were classified following Vertucci's criteria.

Results: All incisors in this study had 1 root. Canines usually had a single root and much less often had 2 roots. Type I and III root canal configurations were found most often, while type $V$ and II configurations were less frequent. Significant compatibility between the left and right side was observed in all evaluated variables. Incisors had the highest symmetry with regard to the number of roots (100\%). Second canals were observed more often in males than females, but only the results in lateral incisors were significant.

Conclusions: This study provides supplemental information for dentists and should help them to better predict the morphology of mandibular anterior teeth in complicated cases in the Polish population. Symmetry was observed in roots and root canal morphology in all examined parameters. (Folia Morphol 2020; 79, 4: 835-844)

Key words: cone-beam computed tomography, canal configuration, root anatomy, symmetry, mandibular incisor, mandibular canine

\section{INTRODUCTION}

Both tooth anatomy and its variability from one patient to another are important factors when considering the proper cleaning of the root canal system and successful endodontic treatment [33]. The omission of a root canal can be catastrophic during endodontic treatment, because some infectious areas could be left intact [29]. Therefore, efficient assessment of

Address for correspondence: Dr. A. Nowicka, Department Conservative Dentistry and Endodontics, Pomeranian Medical University in Szczecin, Al. Powstańców Wlkp. 72, 70-111 Szczecin, Poland, e-mail: nowicka6@gmail.com 
the anatomic pattern of tooth structures should be performed using the most accurate imaging methods, such as conventional periapical radiography and cone-beam computed tomography (CBCT), before endodontic treatment $[10,16]$. Conventional periapical radiography provides two-dimensional (2D) images in which the roots may overlap with the surrounding tissue [32]. CBCT imaging represents an innovative technique that allows the acquisition of three-dimensional (3D) images [14, 19].

In the last decade, Sommer et al. [29] proposed that mandibular incisors generally have a single root and root canal, but subsequent studies showed that there is a high prevalence of 2 canals in mandibular incisors. Further studies focused on root canal configurations and their high variability among different populations $[12,17]$. In the literature, the presence of a second root canal has been observed in $14.1-27.3 \%$ of teeth $[12,17]$. The classification of canals is based on the research of Vertucci, who classified canals into I-VIII types [32]. Subsequent studies of the anatomy of roots revealed the complexity of the root canal system, and their classification system was therefore extended [1, 15, 20, 26].

A review of the literature revealed that using $C B C T$ to assess symmetry in roots and/or root canal morphology in the mandibular anterior teeth has been performed only in Chinese, Turkish, Chongqing, and Israeli populations $[2,12,27,36]$. There is little data in the literature concerning procedures in which two opposite teeth are treated in the same patient, even though this topic is highly clinically relevant [17, 20]. Therefore, the purpose of the study was to analyse mandibular anterior teeth in a Polish population and determine the symmetry of root and root canal morphology between the right and left side using CBCT scanning. The null hypothesis was that there are no differences between the left and right side roots and root canal morphologies of mandibular anterior teeth.

\section{MATERIALS AND METHODS}

\section{Sample selection}

From $111 \mathrm{CBCT}$ examinations performed in the Department of General and Dental Radiology, Pomeranian Medical University in Szczecin, 624 mandibular anterior teeth qualified for an evaluation of their anatomy. Of these, 303 pairs of equivalent teeth on the right and left sides of the same patient were analysed to evaluate symmetry. This study was approved by the Local Ethics Committee of the Pomeranian Medical University in Szczecin (approval number KB-0012/78/02/17). The patients consisted of 47 males and 64 females with ages between 9 and 72 (average, 40.47 years old).

The samples were selected based on the following Han et al. [12] criteria:

1. $C B C T$ images of mandibular anterior teeth with complete root formation were available;

2. Absence of root canal treatment;

3. Absence of coronal or post coronal restorations;

4. Absence of root resorption or periapical lesions;

5. The examined teeth were located in the imaging field.

\section{Image evaluation}

Cone-beam computed tomography images were obtained using a Cranex 3D (No. SE 1100155, Software Version Scanora 5.1.0.9; Soredex, Tuusula, Finland), and source data (the original DICOM images) were imported into image-analysis software (Horos, v. 2.1.1.) and evaluated in the multiplanar reconstruction module of the 3D viewer (Fig. 1). The roots and canals of mandibular anterior teeth were observed independently by two trained investigators. Each tooth was evaluated separately. After virtual isolation of the tooth, its long axis and two other lines perpendicular to the long axis were established (Fig. 1). Axial, sagittal, and cross-sectional slices with a thickness of $0.2-0.25 \mathrm{~mm}$ were used. The contrast and brightness of the images were adjusted using the software to ensure optimal visualisation. The following parameters were recorded and evaluated: tooth position (right or left), the number and shapes of roots, the lengths and widths of teeth, the number of root canals, and the root canal configuration.

1. The number of root canals and their internal patterns were classified according to Vertucci's criteria [32]:

- type I: a single canal appears from the pulp chamber to the apex,

- type II: 2 separate canals leave the pulp chamber but merge into 1 canal at the exit,

- type III: 1 canal leaves the pulp chamber, divides into 2 canals within the root, and then merges at the exit,

- type IV: 2 distinctly separate canals are present from the pulp chamber to the apex,

- type V: a single canal leaves the pulp chamber but divides into 2 canals, 

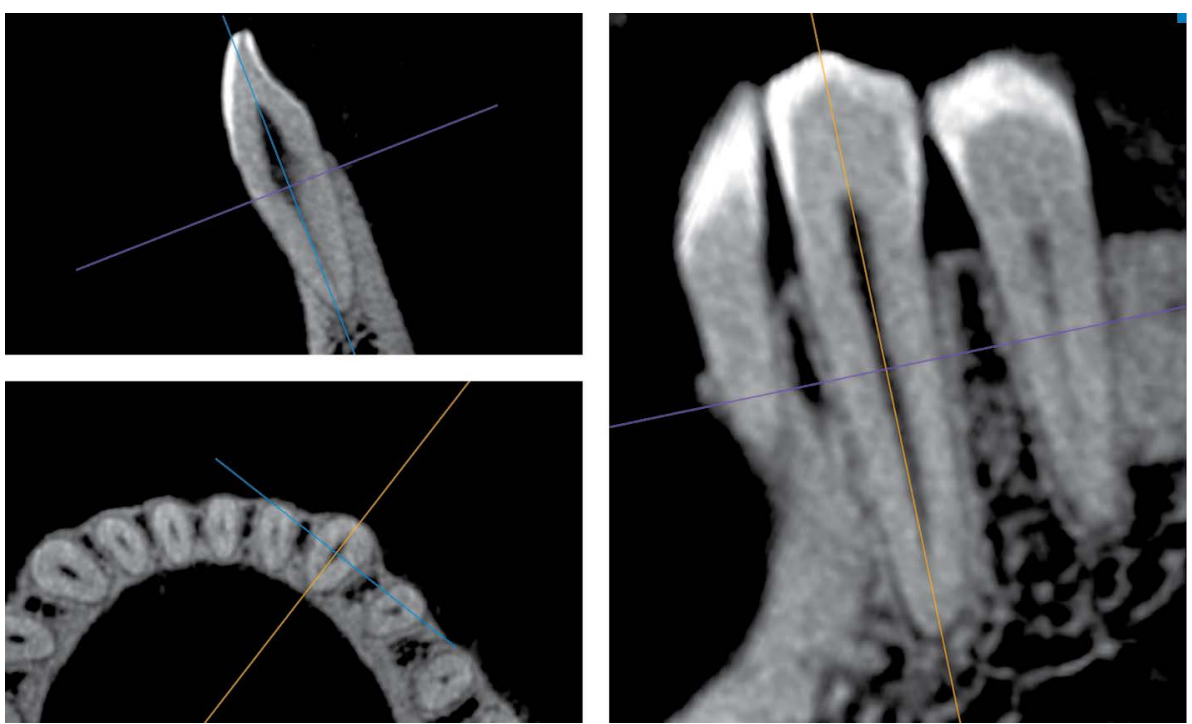

Figure 1. Identification and linear measurements of mandibular anterior teeth in the multiplanar reconstruction module of three-dimensional viewer.

- type VI: 2 separate canals leave the pulp chamber, join at the midpoint, and then divide again into 2 canals with 2 separate apical foramina,

- type VII: 1 canal leaves the pulp chamber, divides into two, unites in the body of the root, and finally divides again into 2 separate canals with 2 separate apical foramina,

- type VIII: 3 separate and distinct canals begin in the pulp chamber and persist to the root apex,

- supplemental types were also renamed, which and these were assigned next numbers type IX (2-1-2-1), type X (1-2-1-2-1) and type XI (1-3);

2. The length of the tooth from edge to apex;

3. The root width at the halfway distance from cementoenamel junction to the apex.

\section{Statistical analysis}

All continuous random variables were verified with the use of the Kolgomorov-Smirnov test due to the normality of their distribution. Verification of significant differences between the two groups was carried out using Student's t-test for independent variables. For continuous variables related to the symmetry between the right and left sides of a tooth, the Mann-Whitney test and Student's t-test were used. Noncontinuous variables are described as the number and frequency of occurrence. For statistical dependences between noncontinuous variables, the $\chi^{2}$ Pearson's test were used. For discreet variables, to verify symmetry between the left and right sides, McNemar and Stuart-Maxwell (marginal homogeneity test) tests were performed. When $p<0.05$, it was understood to indicate that symmetry was not maintained.

Correlations between noncontinuous serial variables as well as nominal and continuous variables were examined using Spearman's and Pearson's tests. The results are described as the correlation coefficient ( $r$ ), and probability ( $p)$, and in Pearson's analysis, the equations for the regression line were also described. Differences in the mentioned tests were considered statistically significant at the probability $p<0.05$. All statistical analyses were performed using the statistical program STATA 11 with the license number 30110532736.

\section{RESULTS}

\section{Anatomy of teeth}

The data showed that central incisors were smaller than lateral incisors. The medium length and width of a central incisor with 1 root canal were 2.05 and $0.53 \mathrm{~cm}$, respectively; the same measurements in lateral incisors were 2.20 and $0.56 \mathrm{~cm}$, respectively; and in canines, they were 2.47 and $0.69 \mathrm{~cm}$, respectively (Table 1). There was a significant relationship between tooth length and width and the number of canals. The parameters analysed above (length and; width) showed that incisors with 2 root canals were higher and significantly wider. The median lengths of canines with 2 root canals were significantly shorter than those of canines with 1 root canal, at 2.28 and $2.47 \mathrm{~cm}$, respectively $(p<0.05$ ) (Table 1$)$. All central 
Table 1. Anatomy of mandibular anterior teeth

\begin{tabular}{|c|c|c|c|c|c|c|c|c|c|c|c|}
\hline \multirow[t]{2}{*}{ Tooth } & \multirow{2}{*}{$\begin{array}{l}\text { Number of root } \\
\text { canals }\end{array}$} & \multicolumn{2}{|c|}{ Gender, N (tooth) } & \multicolumn{4}{|c|}{ Width [cm] } & \multicolumn{4}{|c|}{ Length [cm] } \\
\hline & & $\mathbf{F}$ & M & Min. & Max. & Median & Medium & Min. & Max. & Median & Medium \\
\hline \multirow[t]{4}{*}{ Central incisor } & 1 & 86 & 50 & 0.41 & 0.67 & 0.52 & 0.53 & 1.63 & 2.70 & 2.04 & 2.05 \\
\hline & 2 & 33 & 36 & 0.41 & 0.64 & 0.54 & 0.55 & 1.64 & 2.38 & 2.07 & 2.07 \\
\hline & 3 & 1 & 0 & 0.52 & 0.52 & 0.52 & 0.52 & 2.28 & 2.28 & 2.28 & 2.28 \\
\hline & Pvalue & \multicolumn{2}{|c|}{$>0.05$} & \multicolumn{4}{|c|}{$<0.05$} & & \multicolumn{3}{|c|}{$>0.05$} \\
\hline \multirow[t]{4}{*}{ Lateral incisor } & 1 & 88 & 51 & 0.40 & 0.70 & 0.56 & 0.56 & 1.72 & 2.58 & 2.20 & 2.20 \\
\hline & 2 & 31 & 36 & 0.50 & 0.71 & 0.58 & 0.59 & 1.78 & 2.58 & 2.25 & 2.25 \\
\hline & 3 & 1 & 0 & 0.42 & 0.42 & 0.42 & 0.42 & 1.83 & 1.83 & 1.83 & 1.83 \\
\hline & $P$ value & \multicolumn{2}{|c|}{$<0.05$} & \multicolumn{4}{|c|}{$<0.05$} & & \multicolumn{3}{|c|}{$>0.05$} \\
\hline \multirow[t]{4}{*}{ Canine } & 1 & 99 & 73 & 0.55 & 0.91 & 0.70 & 0.69 & 1.02 & 3.33 & 2.47 & 2.47 \\
\hline & 2 & 18 & 10 & 0.48 & 0.82 & 0.71 & 0.70 & 2.07 & 2.60 & 2.28 & 2.32 \\
\hline & 3 & 1 & 0 & 0.67 & 0.67 & 0.67 & 0.67 & 2.47 & 2.47 & 2.47 & 2.47 \\
\hline & $P$ value & \multicolumn{2}{|c|}{$>0.05$} & \multicolumn{4}{|c|}{$>0.05$} & & \multicolumn{3}{|c|}{$<0.05$} \\
\hline
\end{tabular}

F — female; M - male; Max. — maximum; Min. — minimum
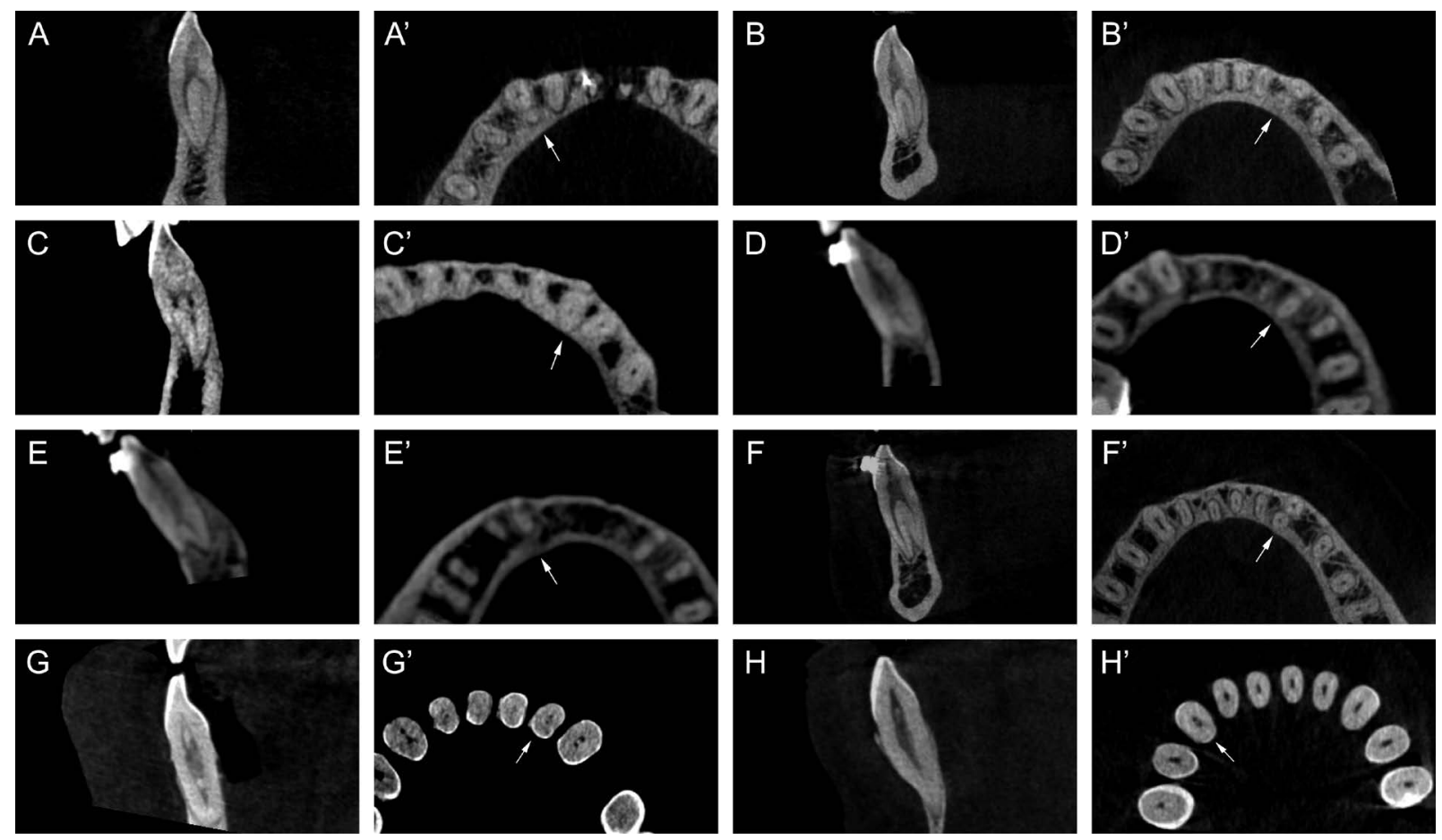

Figure 2. Characteristic images; A, A'-F, F'. Canines with two roots; $\mathbf{G}, \mathbf{G}^{\prime}-\mathbf{H}, \mathbf{H}^{\prime}$. Root canals that leave (divided) the tooth chamber.

and lateral incisors evaluated in this study had 1 root. Canines usually had a single root but much less often had 2 roots (Fig. 2, Table 2).

\section{Anatomy of root canals}

Canal types I and III were observed in all anterior teeth groups of the mandible. Other types were rare and were not present in all groups. The largest proportions of central and lateral incisors and canines had a type I root canal configuration. The next largest configuration was type III (Table 2). Most of the second canals did not extend through the whole root length. In most cases, 1 canal began at the orifice and then divided into 2 before remaining separate canals or fusing again and forming 2 or 1 root foramen, respectively. Alternatively, 2 canals sometimes began from 2 orifices and then fused into 1 canal before separating again or continuing as a single canal (Fig. 3). 
Table 2. Symmetry of mandibular anterior teeth

\begin{tabular}{|c|c|c|c|c|c|c|}
\hline \multirow[t]{2}{*}{ Root canal configuration } & \multicolumn{6}{|c|}{ Tooth, N (\%) } \\
\hline & 31 & 41 & 32 & 42 & 33 & 43 \\
\hline \multicolumn{7}{|l|}{ Number of roots } \\
\hline 1 & $106(100)$ & $106(100)$ & $106(100)$ & $102(100)$ & $92(92)$ & $100(96.15)$ \\
\hline 2 & - & - & - & - & $8(8)$ & $4(3.85)$ \\
\hline \multirow[t]{2}{*}{$\mathrm{N}(\%)$} & \multicolumn{2}{|c|}{1 root $106(100)$} & \multicolumn{2}{|c|}{1 root $102(100)$} & \multicolumn{2}{|c|}{1 root 86 (90.53) } \\
\hline & \multicolumn{2}{|c|}{2 root 0} & \multicolumn{2}{|c|}{2 roots 0} & \multicolumn{2}{|c|}{2 roots 1 (1.05) } \\
\hline Symmetry & \multicolumn{2}{|c|}{+ (yes) } & \multicolumn{2}{|c|}{+ (yes) } & \multicolumn{2}{|c|}{+ (yes) } \\
\hline \multicolumn{7}{|l|}{ Number of root canals } \\
\hline 1 & $69(66.35)$ & $67(64.42)$ & $67(63.21)$ & $72(71.28)$ & $82(82.83)$ & $90(88.24)$ \\
\hline 2 & $34(32.69)$ & $37(35.58)$ & $39(36.79)$ & $28(26.73)$ & $17(17.17)$ & $11(10.78)$ \\
\hline 3 & $1(0.96)$ & - & - & $1(1.98)$ & - & $1(0.98)$ \\
\hline \multirow[t]{2}{*}{$N(\%)$} & \multicolumn{2}{|c|}{1 root canal 58 (54.86) } & \multicolumn{2}{|c|}{2 root canals 24 (23.53) } & \multicolumn{2}{|c|}{1 root canal 55 (56.12) } \\
\hline & \multicolumn{2}{|c|}{2 root canals 20 (19.19) } & \multicolumn{2}{|c|}{1 root canal $70(75.27)$} & \multicolumn{2}{|c|}{2 root canals 4 (19.19) } \\
\hline Symmetry & \multicolumn{2}{|c|}{+ (yes) } & \multicolumn{2}{|c|}{+ (yes) } & \multicolumn{2}{|c|}{+ (yes) } \\
\hline \multicolumn{7}{|l|}{ Type of canal } \\
\hline Type I (1-1) & $69(66.35)$ & $67(64.42)$ & $67(63.21)$ & $72(71.28)$ & $82(82)$ & $90(88.24)$ \\
\hline Type II (2-1) & $2(1.92)$ & - & - & $2(1.98)$ & $4(4)$ & - \\
\hline Type III (1-2-1) & $24(23.07)$ & $31(29.8)$ & $35(33.01)$ & $17(16.83)$ & $4(4)$ & $4(3.85)$ \\
\hline Type IV (2-2) & - & - & - & $1(0.99)$ & $1(1)$ & - \\
\hline Type V (1-2) & $5(4.81)$ & $6(5.78)$ & $3(2.83)$ & $6(4.95)$ & $8(8)$ & $6(5.88)$ \\
\hline Type VI (2-1-2) & - & - & - & - & - & $1(0.98)$ \\
\hline Type VII (1-2-1-2) & $2(1.92)$ & - & - & - & - & - \\
\hline Type VIII (3-3) & - & - & - & - & - & - \\
\hline Type IX (2-1-2-1) & $1(0.96)$ & - & $1(0.96)$ & $1(0.99)$ & - & - \\
\hline Type X (1-2-1-2-1) & - & - & - & $1(0.99)$ & - & - \\
\hline Type XI (1-3) & $1(0.96)$ & - & - & $1(0.99)$ & - & $1(0.98)$ \\
\hline$N(\%)$ & Type & .73) & Type & 6.12) & Typ & $5.27)$ \\
\hline & Type & $3.46)$ & Type & 3.27) & & $.06)$ \\
\hline & & & & $.02)$ & & \\
\hline Symmetry & & & & & & \\
\hline Root canal splitting level & & & & & & \\
\hline No splitting & $69(66.35)$ & $67(64.42)$ & $67(63.21)$ & $72(71.28)$ & $82(82.83)$ & $90(88.24)$ \\
\hline Coronal (c) & $11(10.58)$ & $9(8.65)$ & $14(13.72)$ & $10(9.9)$ & $7(7.07)$ & $4(3.92)$ \\
\hline Middle (m) & $22(20.75)$ & $27(25.96)$ & $23(21.70)$ & $15(14.84)$ & $9(9.09)$ & $8(7.8)$ \\
\hline Middle and apical (ma) & $1(0.96)$ & - & - & - & - & - \\
\hline Apical (a) & $1(0.96)$ & $1(0.96)$ & $2(1.89)$ & $4(3.96)$ & $1(1.01)$ & - \\
\hline$N(\%)$ & No spli & (55.77) & No spli & (56.12) & No spl & (75.53) \\
\hline & & & & & & \\
\hline & & & & & & \\
\hline & & & & & & \\
\hline Symmetry & & & & & & \\
\hline
\end{tabular}

Most other configuration types were type $\mathrm{V}$ or II. Types IV, VI, and VII were also found but at relatively lower frequencies. Type IX (2-1-2-1), type X (1-2-1-2-1) and type XI (1-3) were also observed (Fig. 4).

Canal divisions were observed in the coronal part of the root in $8.65-10.58 \%$ of central incisors, $9.9-13.72 \%$ of lateral incisors, and $3.92-7.07 \%$ of canines. Canal divisions occurred in the middle part of the root in $20.75-25.96 \%$ of central incisors, $14.84-21.70 \%$ of lateral incisors and $7.8-9.09 \%$ of canines (Table 2 ).

In incisors, a second canal was found more often in men than in women, but this difference was only 

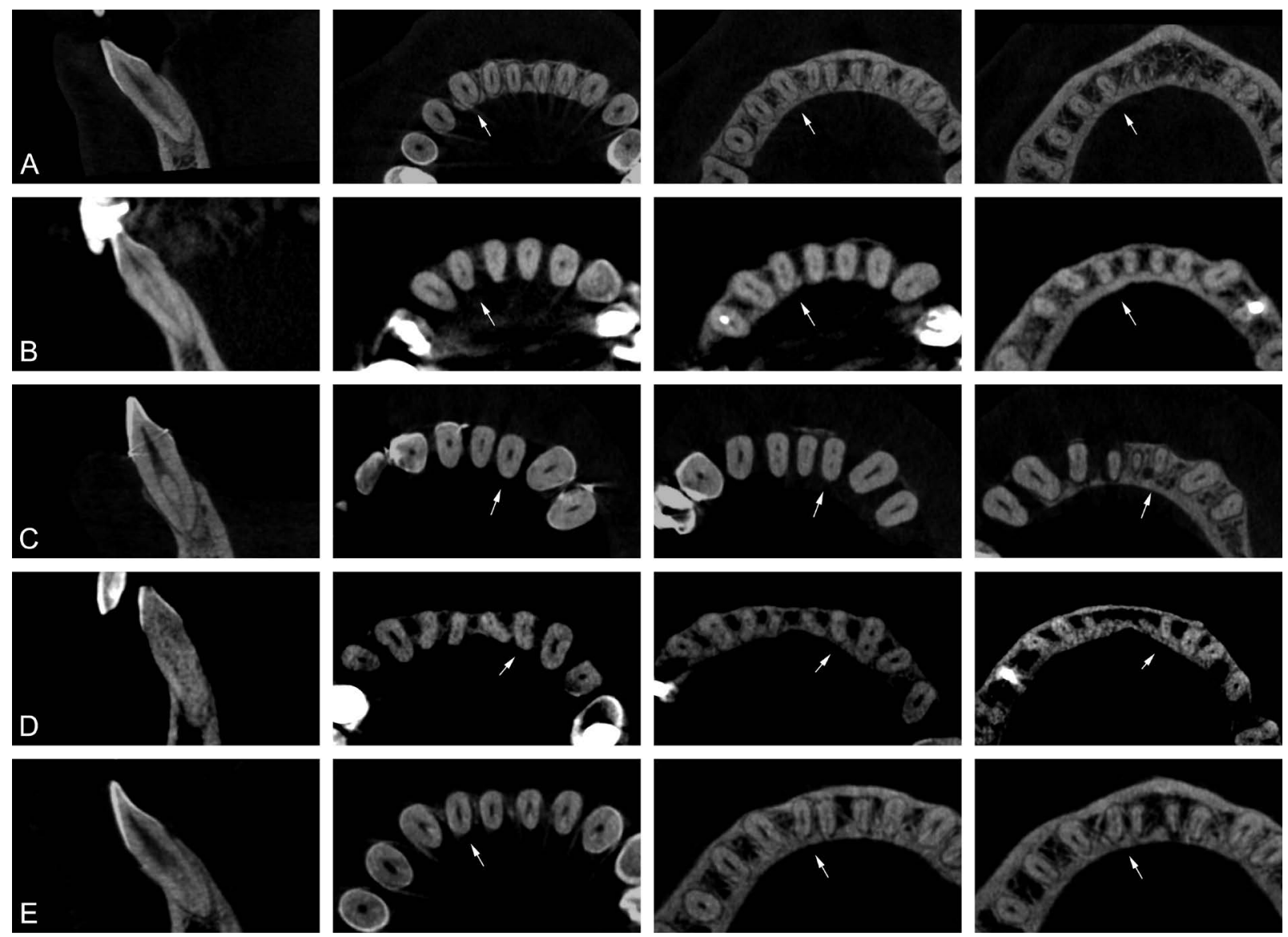

Figure 3. A-E. Root canal configurations, type I-V. Sagittal and axial sections of roots revealed variations in canal morphology; A1-4: type I; B1-4: type II; C1-4: type III; D1-4: type IV; E1-4: type V.

significant in lateral incisors $(p<0.05)$. In canines, women were more likely than men to have 2 canals, but this difference was not significant ( $p>0.05$ ). In each group of teeth, single teeth with 3 canals were observed (Table 1).

\section{Anatomic symmetry}

An analysis of symmetry in roots and root canal morphologies showed that there were no significant differences between right and left side mandibular anterior teeth with regard for the number of roots, the number of canals and the Vertucci type. The highest symmetry in the number of roots was observed in incisors (100\%) (Table 2 ).

\section{DISCUSSION}

Cone-beam computed tomography provides technique for performing a more precise investigation of root canal systems and facilitates a detailed investigation of both the external and the internal anatomy of teeth $[8,9,18,22,23,25]$. Using this approach, tooth anatomy can be simultaneously or separately observed from different angles by reconstructing 3D images, and the characteristics of a tooth can be both qualitatively and quantitatively assessed. CBCT images of teeth can reveal their anatomy in sagittal and horizontal sections $[4,6,12,13,18,20]$. Analyses of the number of roots in mandibular anterior teeth have reported results in different populations: in India, Verma et al. [30] found that $100 \%$ of incisors had a single root; in Iran, Aminsobhani et al. [4] found that all incisors and $96.3 \%$ of canines had 1 root; Martins et al. [20] showed that $100 \%$ of incisors had a single root, while $2.8 \%$ of canines had 2 roots; and in China, by Zhengyan et al. [36] showed that central incisors had a single root (100\%), while lateral incisors and canines had 2 roots in $0.3 \%$ and $0.8 \%$ of cases, respectively. Similar results were observed in Turkey, where Kayaoglu et al. [17] found that $100 \%$ of central incisors were single-rooted, while $0.1 \%$ of lateral incisors and $3.1 \%$ of canines had 2 roots. In our research, all incisors had a single root, while 

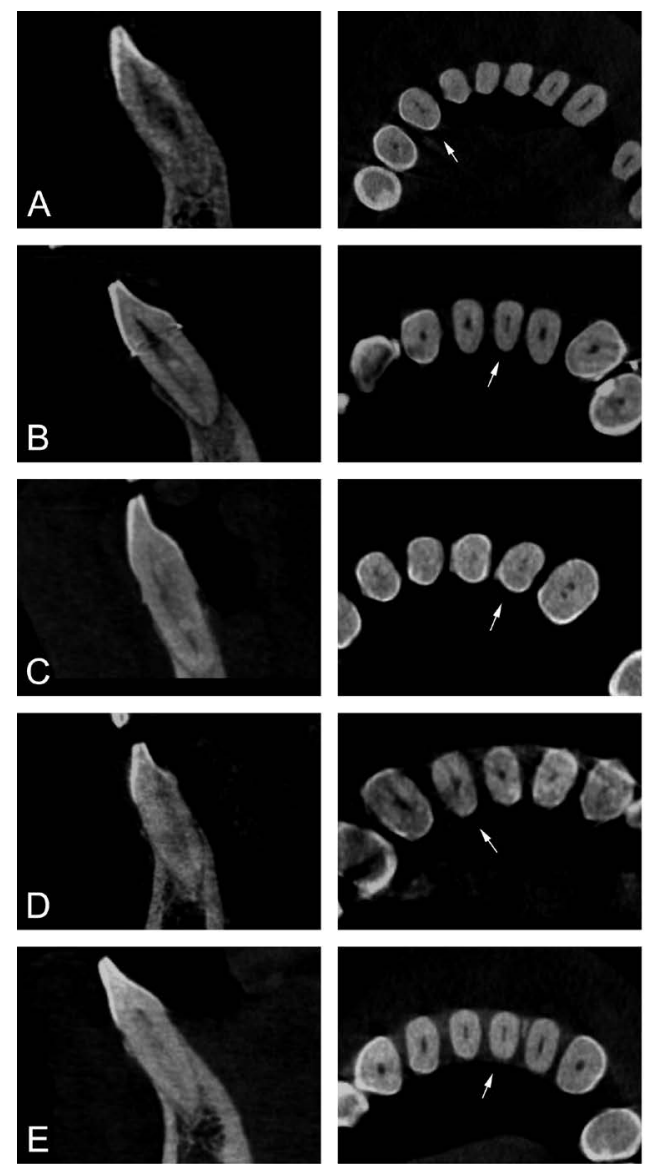
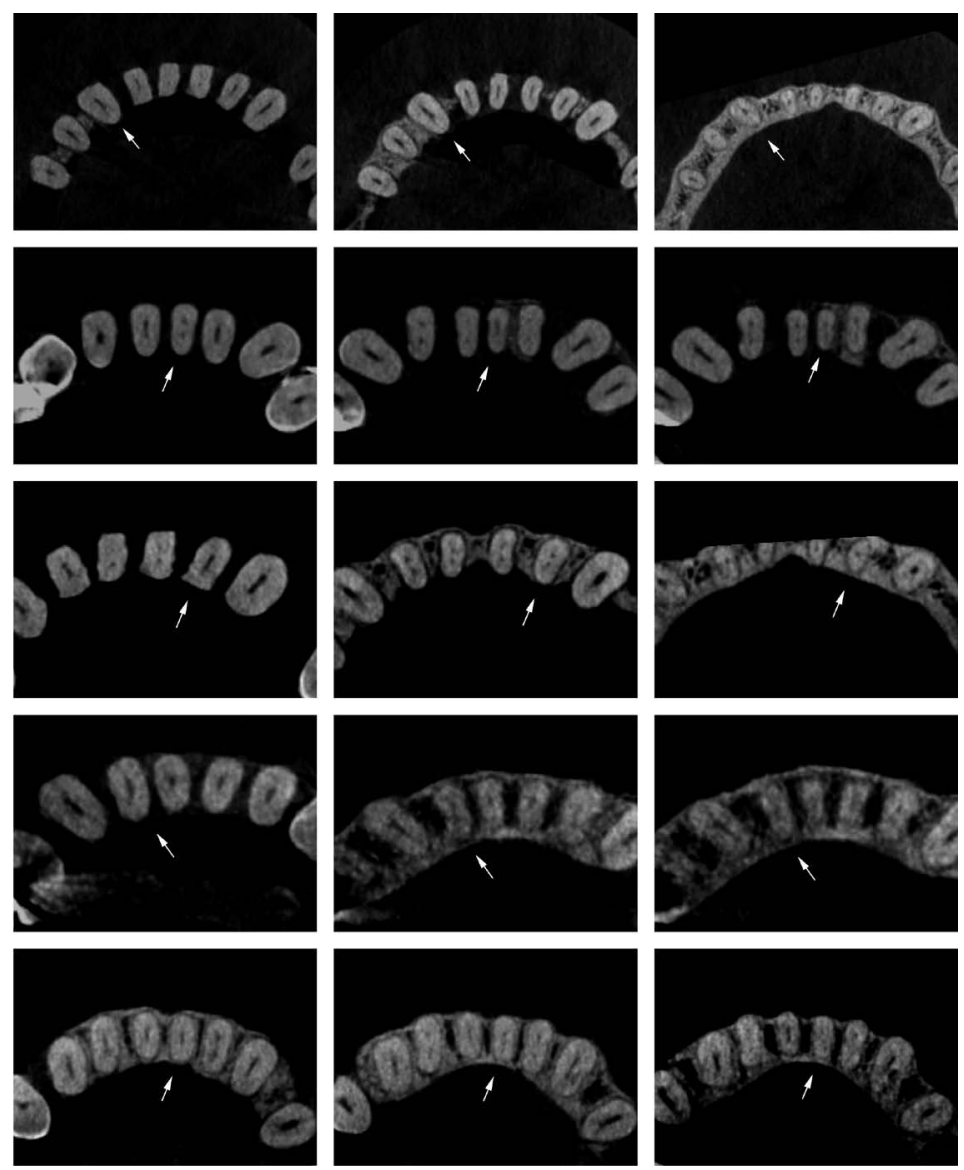

Figure 4. A-E. Root canal configurations, type VI, VII, IX-XI. Sagittal and axial sections of roots revealed variations in canal morphology; A1-4: type VI; B1-4: type VII; C1-4: type IX; D1-4: type X; E1-4: type XI.

2 roots were observed only in canines. The lengths of teeth have been studied in a variety of ways, with some studies evaluating the total lengths of the teeth [4] or the lengths of their roots $[3,28]$ and others studying the length of the crown and the length of the root separately [31]. In our research, we focused our analysis on the total length of the teeth (from cusp to apex). Our measurements showed that the lengths of each group of teeth were slightly longer than those described in Aminsobhani et al. [4].

An analysis of scans showed that not all authors consider the locations of teeth and their postanterior tilt. As a consequence, the dimensions of teeth viewed in axial sections (its anterior-posterior width) are extended [12]. In the course of our own research, we analysed scans in three planes after defining a new axis: the axis of the tooth. After establishing this axis, a dentist can measure the width of the tooth and analyse the configuration of its canals. Our research shows that lateral incisors are wider than central incisors, but this difference was not significant. No similar comparisons were found in the literature.
An analysis of the shapes of root sections revealed some diversity. The mesial and/or distal surfaces often contained long depressions known as radicular grooves in agreement with other studies [36]. Amardeep et al. [3] presented scans of sagittal sections showing the configurations of root canals in which there were visible changes in the structures of the tooth chambers that affected the initial and further course of the canals. These changes in the structure of the chamber matched our observations in teeth with type II and VI configurations. During our research, attention was given to the type 2-1 configuration, and we found that its division in the initial course was based not only on the root canal but also on its connection with the crown of the pulp (Fig. 2). Changes in the chamber contributed to the canal being divided into 2 canals during the initial phase of its course.

Although the types of canals evaluated in this study were based on the classification of Vertucci [32], not all studies have used these I-VIII types. Other studies have also included configurations described in 
Table 3. Prevalences of the canals in central incisors, lateral incisors and canines

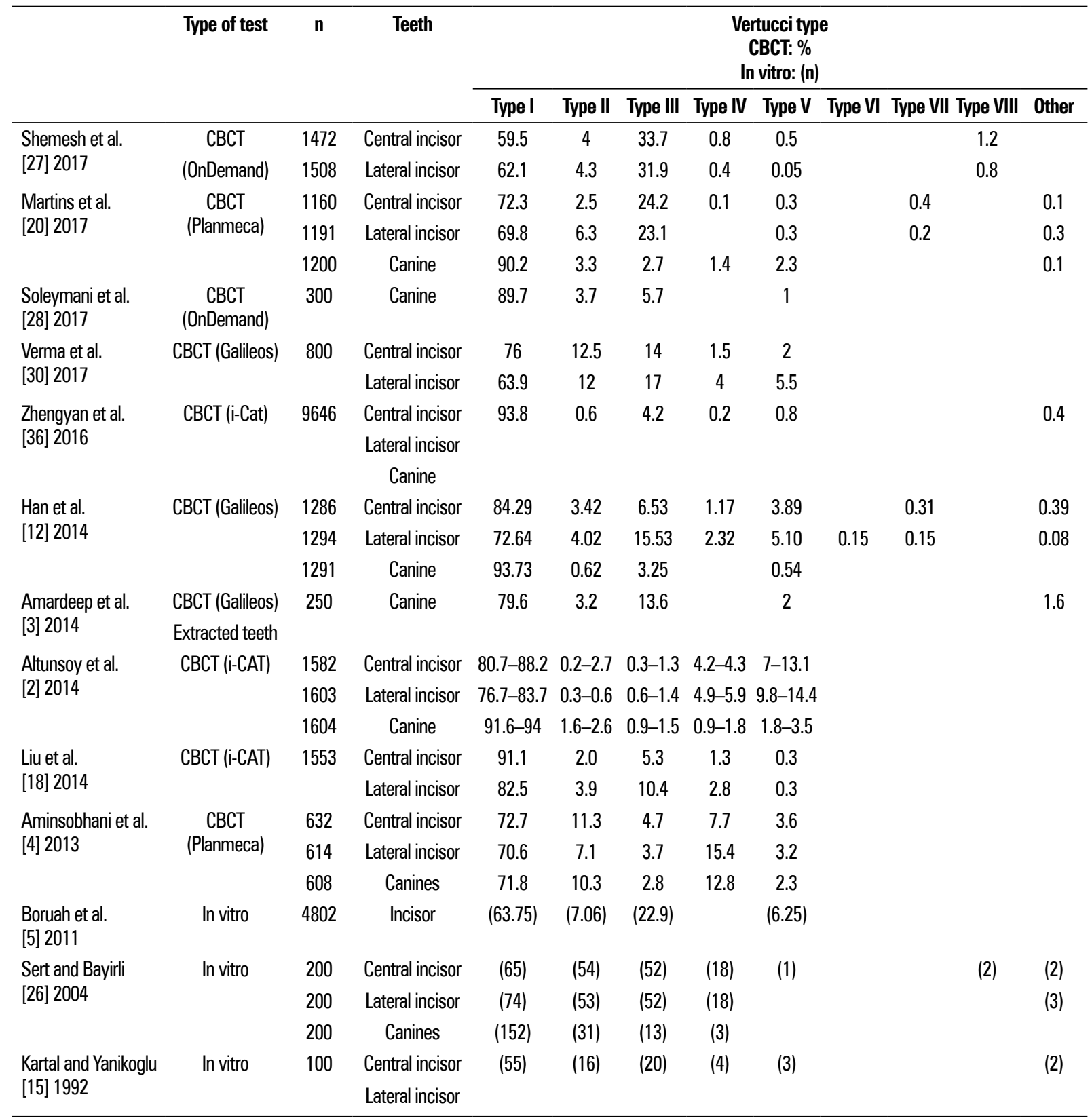

CBCT — cone-beam computed tomography

other less widely cited studies, with some researchers considering only $\mathrm{I}-\mathrm{V}$ types $[2,5,28,30]$. Detailed diagnoses of teeth with rare root canal configurations were performed by Martins et al. [20] and Sert and Bayirli [26]. They observed that supplemental configurations could be marked with subsequent numbers (IX and $\mathrm{X}$, etc.). In analysing the construction of root canals in our study, we observed that a majority of root canal morphologies were type I, followed by types III and V. This finding confirms the observations of other authors, who have found that the most common canal configurations are type I $[2-6,12,15$, $17,28,30]$ or, in the case of 2-canal teeth, type III $[1-3,7,11,12,17,23,27,28,30,36]$. Haghanifar et al. [11] obtained different results; in their study, they observed the following Vertucci types, in order from most to least common: I, III, II, and V. Type V was observed in $0.3 \%$ of teeth. The type I configuration has been shown to be the most common in mandibular anterior teeth (59.5-91.1\%), while the type III configuration has been observed in $2.8-33.7 \%$ and the type $V$ configuration in $0.05-14.4 \%$ of teeth 
$[2-5,12,18,20,28,30]$ (Table 3). The methodology used and the number of tested samples had an influence on whether higher percentages were found in different variations. In the literature, one can also find studies that have evaluated only the number of canals. Previous studies have found that a second canal is observed more often in lateral than in central incisors $[12,18,30]$. However, we found that a second canal was more frequently observed in central incisors than in lateral incisors. A study of the placement of canal divisions was performed by Martins et al. [20]. They found that in central incisors, the most common division occurred in the middle of the root $(17.2 \%)$, while in the lateral incisors, it was in the coronal part (13.3\%). These findings agree with our own observations.

An analysis of symmetry in the morphologies of roots and root canals showed that there were no significant differences between the right and left sides in mandibular anterior teeth [36], mandibular canines [28] and mandibular and maxillary molars [23]. Altunsoy et al. [2] found that there was a likelihood of morphological symmetry in $95 \%$ of cases; this discovery helps dentists to better predict the morphology of canines in complicated cases. Zhengyan et al. [36] found no significant difference in the prevalence of multiroot canals between the left and right sides. In a study by Plotino et al. [23], the rate of symmetry in first mandibular molars was $70.6 \%$, while in maxillary molars, it was $71.1 \%$. With regard for second molars, $81 \%$ of mandibular and $79.6 \%$ of maxillary molars were symmetrical. In our study, there were no statistically significant differences between the right and left sides in symmetry with regard for the number of roots, the number of canals and the Vertucci type.

Research on the relationship between the presence of a second canal in mandibular teeth and sex has produced various results among different studies. According to Verma et al. [30], Zhengyan et al. [36], Kayaoglu et al. [17], second canals are observed more often in women than in men. In study by Verma at al. [30], $15.2 \%$ of men and $20.4 \%$ of women had a second main canal. Zhengyan et al. [36] reported that a second canal was observed in the lateral incisors in $9.4 \%$ of men and $11.9 \%$ of women. This result revealed a significant difference between the sexes $(p<0.05)$. Kayaoglu et al. [17] found no significant difference in this relationship and showed that canines with 2 roots were longer in men than in women in both buccal and lingual roots. Different results were obtained by
Altunsoy et al. [2], Liu et al. [18] and Soleymani et al. [28]. According to their research, the prevalence of teeth with two canals was higher in men than in women. In a study by Liu at al. [18], $14.6 \%$ of males and $11.9 \%$ of females had a second canal, and this difference was not significant $(p>0.001)$. The results of our research were similar: men had second canals more frequently than women, but these results were significant only in lateral incisors. Collectively, we found that observations in different groups of teeth have yielded different results $[7,21,24,34,35]$.

\section{CONCLUSIONS}

This study provides supplemental information for dentists about the anatomy and symmetry of mandibular anterior teeth in a Polish population. All incisors had a single root, while 2 roots were observed only in canines. The largest proportions of central and lateral incisors and canines had a type I root canal configuration, and the next most common configuration was type III. The presence of a second canal in the central and lateral incisors was more prevalent in men than women. Symmetry was observed in roots and root canal morphology in all examined parameters. CBCT is a useful technique for endodontic diagnostics and treatment.

\section{REFERENCES}

1. Ahmed H, Versiani MA, De-Deus G, et al. A new system for classifying root and root canal morphology. Int Endod J. 2017; 50(8): 761-770, doi: 10.1111/iej.12685.

2. Altunsoy M, Ok E, Nur BG, et al. A cone-beam computed tomography study of the root canal morphology of anterior teeth in a Turkish population. Eur J Dent. 2014; 8(3): 302-306, doi: 10.4103/1305-7456.137630, indexed in Pubmed: 25202207.

3. Amardeep NS, Raghu S, Natanasabapathy V. Root canal morphology of permanent maxillary and mandibular canines in Indian population using cone beam computed tomography. Anat Res Int. 2014; 2014: 731859, doi: 10.1155/2014/731859, indexed in Pubmed: 24895538.

4. Aminsobhani M, Sadegh M, Meraji N, et al. Evaluation of the root and canal morphology of mandibular permanent anterior teeth in an Iranian population by cone-beam computed tomography. J Dent (Tehran). 2013; 10(4): 358-366, indexed in Pubmed: 24396355.

5. Boruah LC, Bhuyan AC. Morphologic characteristics of root canal of mandibular incisors in North-East Indian population: An in vitro study. J Conserv Dent. 2011; 14(4): 346-350, doi: 10.4103/0972-0707.87195, indexed in Pubmed: 22144800.

6. Bürklein $S$, Heck R, Schäfer E. Evaluation of the root canal anatomy of maxillary and mandibular premolars in a selected german population using cone-beam computed tomographic data. J Endod. 2017; 43(9): 1448-1452, doi: 10.1016/j. joen.2017.03.044, indexed in Pubmed: 28743430.

7. Caputo BV, Noro Filho GA, de Andrade Salgado DM, et al. Evaluation of the root canal morphology of molars by using cone-beam computed tomography in a brazilian population: 
part I. J Endod. 2016; 42(11): 1604-1607, doi: 10.1016/j. joen.2016.07.026, indexed in Pubmed: 27625147.

8. Chen IP, Tadinada A, Dutra EH, et al. Dental anomalies associated with craniometaphyseal dysplasia. J Dent Res. 2014; 93(6): 553-558, doi: 10.1177/0022034514529304, indexed in Pubmed: 24663682.

9. Estrela C, Bueno MR, Leles CR, et al. Accuracy of cone beam computed tomography and panoramic and periapical radiography for detection of apical periodontitis. J Endod. 2008; 34(3): 273-279, doi: 10.1016/j.joen.2007.11.023, indexed in Pubmed: 18291274.

10. Ghobashy AM, Nagy MM, Bayoumi AA. Evaluation of root and canal morphology of maxillary permanent molars in an Egyptian population by cone-beam computed tomography. J Endod. 2017; 43(7): 1089-1092, doi: 10.1016/j. joen.2017.02.014, indexed in Pubmed: 28476465.

11. Haghanifar S, Moudi E, Bijani A, et al. Morphologic assessment of mandibular anterior teeth root canal using CBCT. Acta Med Acad. 2017; 46(2): 85-93, doi: 10.5644/ ama2006-124.193, indexed in Pubmed: 29338272.

12. Han $T, M a Y$, Yang $L$, et al. A study of the root canal morphology of mandibular anterior teeth using conebeam computed tomography in a Chinese subpopulation. J Endod. 2014; 40(9): 1309-1314, doi: 10.1016/j. joen.2014.05.008, indexed in Pubmed: 25043332.

13. Johnsen GF, Dara S, Asjad S, et al. Anatomic comparison of contralateral premolars. J Endod. 2017; 43(6): 956-963, doi: 10.1016/j.joen.2017.01.012, indexed in Pubmed: 28377148.

14. Karabucak B, Bunes A, Chehoud C, et al. Prevalence of apical periodontitis in endodontically treated premolars and molars with untreated canal: a cone-beam computed tomography study. J Endod. 2016; 42(4): 538-541, doi: 10.1016/j. joen.2015.12.026, indexed in Pubmed: 26873567.

15. Kartal N, Yanıkoğlu F. Root canal morphology of mandibular incisors. J Endod. 1992; 18(11): 562-564, doi: 10.1016/ s0099-2399(06)81215-x.

16. Kashyap RR, Beedubail SP, Kini R, et al. Assessment of the number of root canals in the maxillary and mandibular molars: A radiographic study using cone beam computed tomography. J Conserv Dent. 2017; 20(5): 288-291, doi: 10.4103/JCD.JCD_73_17, indexed in Pubmed: 29386772.

17. Kayaoglu G, Peker I, Gumusok M, et al. Root and canal symmetry in the mandibular anterior teeth of patients attending a dental clinic: CBCT study. Braz Oral Res. 2015; 29, doi: 10.1590/1807-3107BOR-2015.vol29.0090, indexed in Pubmed: 26154376.

18. Liu J, Luo J, Dou L, et al. CBCT study of root and canal morphology of permanent mandibular incisors in a Chinese population. Acta Odontol Scand. 2014; 72(1): 26-30, doi: 10.3109/00016357.2013.775337, indexed in Pubmed: 24255962.

19. Maret D, Molinier F, Braga J, et al. Accuracy of 3D reconstructions based on cone beam computed tomography. J Dent Res. 2010; 89(12): 1465-1469, doi: 10.1177/0022034510378011, indexed in Pubmed: 20929716.

20. Martins JNR, Marques D, Mata A, et al. Root and root canal morphology of the permanent dentition in a Caucasian population: a cone-beam computed tomography study. Int Endod J. 2017; 50(11): 1013-1026, doi: 10.1111/ iej.12724, indexed in Pubmed: 27883205.

21. Ozcan G, Sekerci $A E$, Cantekin $K$, et al. Evaluation of root canal morphology of human primary molars by using $C B C T$ and comprehensive review of the literature. Acta Odontol Scand. 2016; 74(4): 250-258, doi: 10.3109/00016357.2015.1104721, indexed in Pubmed: 26523502.

22. Pérez-Heredia $M$, Ferrer-Luque $C M$, Bravo $M$, et al. Conebeam computed tomographic study of root anatomy and canal configuration of molars in a spanish popula- tion. J Endod. 2017; 43(9): 1511-1516, doi: 10.1016/j. joen.2017.03.026, indexed in Pubmed: 28735786.

23. Plotino G, Tocci L, Grande NM, et al. Symmetry of root and root canal morphology of maxillary and mandibular molars in a white population: a cone-beam computed tomography study in vivo. J Endod. 2013; 39(12): 1545-1548, doi: 10.1016/j.joen.2013.09.012, indexed in Pubmed: 24238444.

24. Ratanajirasut R, Panichuttra A, Panmekiate S. A cone-beam computed tomographic study of root and canal morphology of maxillary first and second permanent molars in a thai population. J Endod. 2018; 44(1): 56-61, doi: 10.1016/j. joen.2017.08.020, indexed in Pubmed: 29061352.

25. Rodríguez G, Patel S, Durán-Sindreu F, et al. Influence of conebeam computed tomography on endodontic retreatment strategies among general dental practitioners and endodontists. J Endod. 2017; 43(9): 1433-1437, doi: 10.1016/j. joen.2017.04.004, indexed in Pubmed: 28689702.

26. Sert S, Bayirli GS. Evaluation of the root canal configurations of the mandibular and maxillary permanent teeth by gender in the Turkish population. J Endod. 2004; 30(6): 391-398, doi: 10.1097/00004770-200406000-00004, indexed in Pubmed: 15167464.

27. Shemesh A, Kavalerchik E, Levin A, et al. Root canal morphology evaluation of central and lateral mandibular incisors using cone-beam computed tomography in an Israeli Population. J Endod. 2018; 44(1): 51-55, doi: 10.1016/j. joen.2017.08.012, indexed in Pubmed: 29033082.

28. Soleymani A, Namaryan N, Moudi E, et al. Root canal morphology of mandibular canine in an iranian population: a CBCT assessment. Iran Endod J. 2017; 12(1): 78-82, doi: 10.22037/iej.2017.16, indexed in Pubmed: 28179930.

29. Sommer RF, Ostrander FD, Crowley M. Clinical Endodontics, 2nd ed. WB Saunders, Philadelphia, PA 1965: 269-271.

30. Verma GR, Bhadage C, Bhoosreddy AR, et al. Cone beam computed tomography study of root canal morphology of permanent mandibular incisors in indian subpopulation. Pol J Radiol. 2017; 82: 371-375, doi: 10.12659/ PJR.901840, indexed in Pubmed: 28794810.

31. Versiani MA, Pécora JD, Sousa-Neto MD. Microcomputed tomography analysis of the root canal morphology of single-rooted mandibular canines. Int Endod J. 2013; 46(9): 800-807, doi: 10.1111/iej.12061, indexed in Pubmed: 23402296

32. Vertucci FJ. Root canal anatomy of the human permanent teeth. Oral Surg Oral Med Oral Pathol. 1984; 58(5): 589-599, doi: 10.1016/0030-4220(84)90085-9, indexed in Pubmed: 6595621.

33. Vertucci F. Root canal morphology and its relationship to endodontic procedures. Endod Top. 2005; 10(1): 3-29, doi: 10.1111/j.1601-1546.2005.00129.x.

34. Tian YY, Guo B, Zhang R, et al. Root and canal morphology of maxillary first premolars in a Chinese subpopulation evaluated using cone-beam computed tomography. Int Endod J. 2012; 45(11): 996-1003, doi: 10.1111/j.13652591.2012.02059.x, indexed in Pubmed: 22551454.

35. Yang H, Tian C, Li G, et al. A cone-beam computed tomography study of the root canal morphology of mandibular first premolars and the location of root canal orifices and apical foramina in a Chinese subpopulation. J Endod. 2013; 39(4): 435-438, doi: 10.1016/j.joen.2012.11.003, indexed in Pubmed: 23522531.

36. Zhengyan Y, Keke Lu, Fei W, et al. Cone-beam computed tomography study of the root and canal morphology of mandibular permanent anterior teeth in a Chongqing population. Ther Clin Risk Manag. 2016; 12: 19-25, doi: 10.2147/TCRM.S95657, indexed in Pubmed: 26730198. 